tracheal tube, softened by warming, can facilitate employment of a fine, very flexible fibrescope for endotracheal intubation.

Two cases are reported in which a fibreoptic nasopharyngoscope was used to intubate the trachea in patients whom it would have been difficult or impossible to intubate with a rigid laryngoscope.

\section{Case \#1}

A 48-yr-old woman with severe deforming rheumatoid arthritis presented for cosmetic rhinoplasty. Clinical examination revealed micrognathia and a rigid cervical spine, fixed in moderate flexion. Mouth opening was limited to $1.5 \mathrm{~cm}$ between tips of incisors. Cervical spine $x$-rays revealed no instability. There was no neurological deficit. Both patient and surgeon expressed preference for general anaesthesia. Consultations with her rheumatologist and a general internist confirmed that she had no serious haematological, cardiac, renal or pulmonary complications, and it was considered that if her airway could be managed safely, the likely benefits of the procedure outweighed the risks. This was discussed at length with the patient, who was advised that awake intubation would be attempted and, if unsuccessful, the procedure would be cancelled.

With the surgeon standing by, and after $i v$ sedation with midazolam $2 \mathrm{mg}$ and glycopyrrolate $0.2 \mathrm{mg}$, topical anaesthesia with xylocaine $4 \%$ was achieved by gargling. Fibreoptic laryngoscopy was easily performed using a Pentax FNL-10S nasopharyngoscope (length of insertion tube $=300 \mathrm{~mm}$, diameter of insertion tube $=3.5 \mathrm{~mm}$ ). Because the endoscope had no suction channel, the larynx was sprayed with $2 \mathrm{ml}$ xylocaine $4 \%$ through a cricothyroid puncture (using a $25 \mathrm{G}$ needle). Oral intubation over the fibrescope with a softened $6.5 \mathrm{~mm}$ endotracheal tube was then performed without difficulty or coughing. General anaesthesia was induced and the surgery performed without incident.

\section{Case \#2}

A 40-yr-old woman in good health presented for cosmetic rhinoplasty. Having had a previous LeFort procedure and with mouth opening limited to $2 \mathrm{~cm}$, she was known to be "a difficult intubation." She had undergone awake fibreoptic intubation before, and understood and accepted the need for it. After sedation and topical anaesthesia as in case \#1, orotracheal intubation was performed without incident using the fibreoptic nasopharyngoscope. After general anaesthesia and muscle relaxation were induced, an attempt was made to visualize the larynx with a Magill \#3 laryngoscope blade. It was impossible to see the base of the tongue, let alone the larynx.

These cases show that even a very light flexible fi- brescope may be used successfully for adult orotracheal intubation, using a small, warmed endotracheal tube. Erikson $^{4}$ described the use of a similar instrument for nasal (nor oral) intubation, but used it rather to bend the longer naso-tracheal tube (he lined up the end of the tube with the end of the fibrescope) and direct it towards the larynx which he manipulated digitally, to move the glottis into line with the tube. This was in contrast to the method used here, of using the fibrescope like a guide wire in the Seldinger technique. It is not suggested that the nasopharyngoscope be chosen instead of the bronchoscope, but that in the absence of the latter, the former may be employed rather than abandoning the procedure or resorting to other potentially more traumatic methods such as a blind retrograde technique.

\section{A.F.D. Cole MD \\ Department of Anaesthesia \\ Mount Sinai Hospital \\ Toronto}

\section{REFERENCES}

1 Benumof $J L$. Management of the difficult adult airway. Anesthesiology 1991; 75: 1087-110.

2 Witton TH. An introduction to the fiberoptic laryngoscope. Can J Anaesth 1981; 28: 475-8.

3 Ovassapion A. Fiberoptic Airway Endoscopy in Anesthesia and Critical Care. Raven Press, New York, 1990, 6.

4 Eriksen $S$. The fiberoptic rhinoscope in adult intubation. Anesthesiology 1986; 64: 128-9.

\section{Tracheal intubation and cervical injury}

To the Editor:

I have read with interest the dialogue between Drs. Drummond and Crosby in the Correspondence section of the November, 1992 issue $^{1}$ regarding the best method for the elective intubation of the cervical spine-injured patient.

I had the misfortune of intubating fibreoptically awake and anaesthetizing a 77-yr-old Class 4 ASA patient with ankylosing spondylitis who had sustained a fracture dislocation of $\mathrm{C}_{5-6}$. Tragically, he developed quadriplegia postoperatively. The first "expert witness" for the plaintiff, an 86-yr-old neurosurgeon who hadn't operated since 1976, testified that not performing a tracheostomy "constituted a wanton disregard of principles." The second "expert witness" for the plaintiff, a disabled neurosurgeon, testified that I hyperextended the patient's neck during 
intubation after induction of general anaesthesia - both contraindicated. He later admitted he had never looked at the anaesthesia record.

At least in the United States, the medical-legal considerations may well influence what technique the anaesthetist recommends or chooses to secure the airway in the cervical injured patient requiring surgery. Although not best medically, the old method of pre-operative awake tracheostomy may be the most realistic and defensible for the anaesthetist. Should the anaesthetist be willing to assume the risk of securing the airway, some form of awake intubation followed by a thorough and documented neurological evaluation and after positioning appears to be the most judicious approach.

Anthony R. Palmer MD

907-B Medical Centre Drive

Arlington, TX 76012

\section{REFERENCE}

1 Tracheal intubation and cervical injury. Can $\mathbf{J}$ Anaesth 1992; 39: 1000-1.

\section{Upper airway obstruction by Ascaris worm}

To the Editor:

A 52-yr-old male patient was admitted to the Intensive Care Unit (ICU) for postoperative ventilation. He had earlier developed severe hypovolaemic shock following lumbar discectomy, for which a laparotomy had been performed to repair an aortic tear. After two hours of mechanical ventilation in ICU, the trachea was extubated and he was fully conscious and in no distress. One halfhour later, the patient suddenly developed severe stridor and became cyanosed. Urgent preparations were made to reintubate the trachea, but the patient coughed up a long object, which was found to be a $22 \mathrm{~cm}$ Ascaris worm (Figure). Immediately, the stridor disappeared and the patient's colour returned to normal.

Upper airway obstruction is a life-threatening medical emergency. Common causes are foreign bodies or inflammation, but upper airway obstruction of this nature is rarely reported.' Adult Ascaris Lumbricoides worms may migrate up to the oesophagus and enter the air passages, especially when they are irritated by certain drugs or anaesthetic agents. ${ }^{2,3}$ Acute laryngeal obstruction due to Ascaris worm, despite its rarity, should be considered, especially in areas of endemic parasitic infestation.

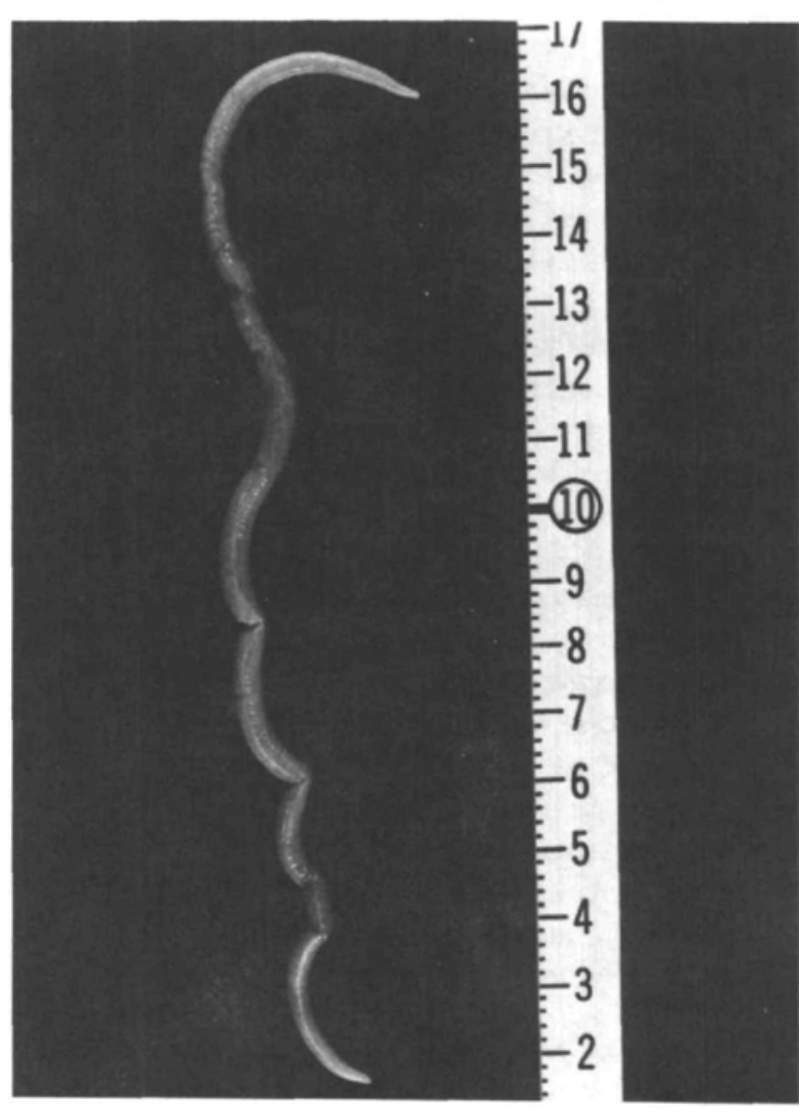

FIGURE Ascanis worm removed from the patient.

Treatment of Ascariasis before elective surgery is indicated. $^{3}$

Jafar H. Faraj MB ChB DA FFARCS

38 Harradence Close

Winnipeg, Manitoba R3Y IK5

\section{REFERENCES}

1 Solomon E. Leech - an unusual cause of (laryngotracheal) obstruction. Ethiopian Medical Journal, 1991; 29: 141.

2 Markell EK, Voge M, John DT. Medical Parasitology, 7th ed. W.B. Saunders Company, 1992, Chapter 8: 264.

3 Schroeder SA, Tierney LM, McPhee SJ, Papadakis MA, Krupp MA. Current Medical Diagnosis and Treatment. A Lang Medical Book, 1992, Chapter 29, 1133.

\section{Pre-admission clinic}

\section{To the Editor:}

We appreciate your publishing the results of the initiation of our Pre-Admission Anaesthetic Consultation Clinic.' 